still occurs in industry in conditions in which men are exposed to lubricating oils.

Although the first synthetic dyestuffs were made in England by Perkin, the German chemical industry was the first to exploit the discoveries and manufacture dyestuffs on a large scale. It was in Germany that the first cases of bladder cancer due to exposure to aromatic amines were reported by Rehn in 1895. The development of dyestuffs industries in other countries was associated with widespread increases in the incidence of bladder cancer. Cases of bladder cancer in men who had manufactured dyestuffs intermediates including 2-naphthylamine and benzidine in England were reported by Wignall in 1929. Another aromatic amine, 4-aminobiphenyl, had been manufactured and used in the United States for many years. The intelligent anticipation and laboratory work of Williams and his colleagues (1952), showing that it was carcinogenic to animals, prevented the manufacture of this compound in Britain and other countries. In 1955 evidence was presented showing that this compound had caused cancer in men occupied with its manufacture.

In addition to their use in dyestuff manufacture, aromatic amines were used in the rubber industry. Case and Hosker in 1954 found an increased

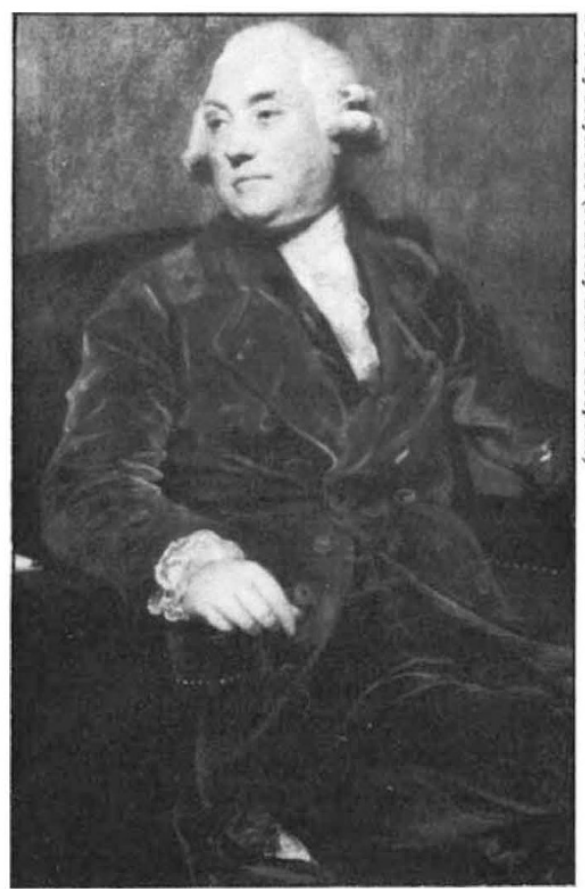

incidence of bladder cancer in rubber workers in one region of England. It is probable that carcinogenic aromatic amines have not been used in the rubber industry since 1950 and because of the possible hazard special facilities for early diagnosis have been available for 20 years. Cancer of the bladder has been a prescribed disease in Britain since 1953.
Early in the present century Japanese workers demonstrated that the application of coal tar to the ears of rabbits or the skin of mice induced tumours some of which were malignant. This provides a bioassay of carcinogenic activity which Kennaway and his colleagues used to identify the hydrocarbon 1, 2.5, 6-dibenzanthracene as the first known compound to induce cancer and then for the isolation and characterisation of 3, 4-benzopyrene from coal tar. Carcinogenic aromatic amines and polycyclic hydrocarbons were known 40 years ago, but in spite of much research the mechanisms by which they exert their carcinogenic actions are still not exactly known.

The knowledge of the chemical nature of the carcinogens, which must have been present in the soot that caused cancer in the young chimney sweeps described by Percival Pott, has in some cases helped with the problems of reducing the hazard of environmental carcinogens. Many other extrinsic cancer-producing agents have been discovered. As most cancers in man are probably caused by extrinsic factors, many still remain to be identified. The discovery of these and the removal or reduction of them in the environment will decrease the incidence of cancer in the way started by the English surgeon two hundred years ago.
$\mathrm{T}^{\mathrm{n}}$ HE young scientist who wants to
venture into medical research now faces an acute problem in finding a satisfactory career structure. It used to be that workers in this field had some form of tenure, either through their contract or through a moral obligation readily acknowledged by the employer. But the trend in recent years has been to offer only temporary appointments lasting, at most, five years. This poses severe problems.

The really outstanding person will always find help elsewhere if the support runs out, of course. My concern is more for the capable and well qualified scientist. Three to five years of medical research may actually prove to be a handicap when competing for teaching or research posts with candidates who have pursued a more academic path.

The Medical Research Council have recently recognised the problem in their own establishments by ensuring that tenure will be granted to staff no later than in their mid-30s-other institutions will probably fall into line. But this only accounts for 20-30 people annually. Numerous first-rate scientists better equipped for work in applied medical research are still un-

\section{Career medicine}

regularly on an equal footing. (Contrast this with the United States where young doctors may undergo a long in basic science and later to five years in medical research might become competent to direct highly be required to take a diploma in Bioadvanced work in a hospital labora- Medical Science. These courses would tory.) Such teams at present exist in provide a general clinical background advanced institutes and in them the to the problems in which the hospital scientist (who often makes the early laboratories play a major role a large running) has learnt to communicate proportion of the lectures being given successfully with the clinician. Might by medical staff. This would be far not such teams be introduced more less expensive for the country than widely in medical schools and general the training of medical graduates in hospitals? They could be a highly advanced laboratory methods, in addiefficient means of speeding the accept- tion to their medical training. Such a ance by clinicians of the most recent scheme could provide a career strucadvances in laboratory methods. And ture for those scientists at present in might not this be a solution to the medical research who have a most career problem for medical scientists? uncertain future.-E. J. Ambrose. 